\title{
Patients are harmed (again), fingers point. What's wrong?
}

A patient is misdiagnosed with breast cancer and undergoes needless surgery. The public is informed only after it happens again; confidence is shaken. Additional concerns about pathology services arise and an external review is completed. The report names one surgeon and one pathologist, numerous issues are highlighted, including an unhealthy organizational culture, and several fixes are recommended. ${ }^{1}$

Will care be safer? This is not a trivial question, nor are these cases isolated events. Similar cases across the country have come to light in recent years why does this keep happening?

There are no simple answers. Health care is intensely complex and the safety issues that need to be addressed for the core functions of care - keeping people healthy, making people better, managing chronic disease and end-of-life care are all very different. For example, pathologists require cognitive expertise or being good thinkers, in contrast to emergency physicians, who also require "procedural expertise." ${ }^{2}$

Health care will never be made substantially safer by focusing after the fact on individual providers. Furthermore, naming, blaming and shaming individuals for doing things we are all capable of, never makes a system safer — and may have the opposite effect. Health care organizations that try to restore public confidence by punishing individuals suffer from the "vulnerable system syndrome."'3 The syndrome is characterized by three elements: blaming frontline individuals, denying the potential for catastrophes, and mistakenly pursuing the "wrong type of excellence" with a focus on production and finance performance targets. ${ }^{3}$

This is not to say that post-event performance evaluation is not important in some cases. However, the sweet spot for safer patient care lies in the continual evaluation and improvement of processes used to deliver care, as well as structural elements of the system that support care delivery, for example, environment and equipment factors.

Governments, leaders of health care organizations, health care providers and educators would be well served by (re)reading the National Steering Committee on Patient Safety 2002 report. One of its principles for action was "to

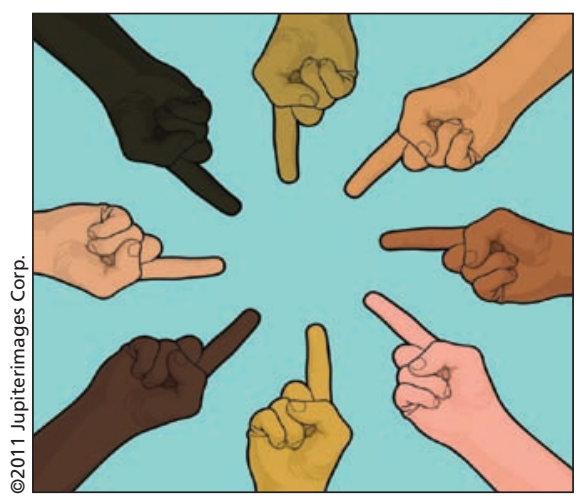

develop, maintain and nurture a culture of safety." ${ }^{4}$ This phrase refers to four specific but interdependent components. The "safety culture" of an organization requires a "reporting culture," ${ }_{5}$ where workers submit reports reactively about close calls and events leading to harm, as well as proactively about hazards and hazardous situations. Such reporting only takes place within a "just culture," characterized by an atmosphere of trust, in which people are encouraged, even rewarded, for providing essential safetyrelated information. However, organization must also draw the line "between acceptable and unacceptable behaviour." There should be sanctions for individuals who intentionally harm patients or who are recklessly noncompliant with accepted standards.

An organization that is both "just" and "reporting" will be better able to use information garnered both internally and externally and so become a "learning organization." Organizations must also be able to draw the right conclusions and have the will to implement major reforms. One such reform involves developing the ability to shift power during crises from the top of the bureau- cracy to "task experts on the spot." Organizations that have evolved in this way have developed a "flexible culture."5

Taken together, these four attributes - reporting, just, learning and flexible - characterize an "informed organization." ${ }_{5}$ And as the currency of safety for any organization is its safetycritical information, an organization rich in information (gathered appropriately, learned from, and applied) is said to have a safety culture.

To make care safer, those individuals charged with funding and governing health care systems in Canada must demonstrate informed, principle-based, consistent leadership. Redeployment of resources for improving safety is also badly needed, so that care can be improved in a systematic way across the entire health system. Finally, an investment in the will to do so, rather than continued complaints about the lack of safe care, should benefit patients who will be spared harm, and also the system intent on helping them. Safer patients are cheaper patients.

\section{W. Ward Flemons MD \\ Professor of medicine \\ Jan M. Davies MSc MD \\ Professor of anesthesia and adjunct professor of psychology \\ University of Calgary \\ Calgary, Alta.}

\section{References}

1. Report of the Investigators of Surgical and Pathology Issues at Three Essex County Hospitals: HôtelDieu Grace Hospital, Leamington District Memorial Hospital and Windsor Regional Hospital. The Investigators of Surgical and Pathology Issues at Three Essex County Hospitals; 2010.

2. Croskerry P. The cognitive imperative: thinking about how we think. Acad Emerg Med 2000;7:1223-31.

3. Reason JT, Carthey J, de Leval MR. Diagnosing "vulnerable system syndrome": an essential prerequisite to effective risk management. Qual Health Care 2001; 10:ii21-5.

4. National Steering Committee on Patient Safety. Building a safer system. A national integrated strategy for improving patient safety in Canadian health care. Ottawa $(\mathrm{ON})$ : The Royal College of Physicians and Surgeons of Canada; 2002.

5. Reason J. Managing the risks of organizational accidents. Aldershot (UK): Ashgate Publishing Company; 1997.

CMAJ 2011. DOI:10.1503/cmaj.101389

All editorial matter in CMAJ represents the opinions of the authors and not necessarily those of the Canadian Medical Association. 